\title{
Optimization on TEEN routing protocol in cognitive wireless sensor network
}

\author{
Yanhong $\mathrm{Ge}^{1,2}$, Shubin Wang ${ }^{1^{*}}$ (D) and Jinyu $\mathrm{Ma}^{1}$
}

\begin{abstract}
In order to improve the energy efficiency of cognitive wireless sensor network, this paper introduces threshold-sensitive energy efficient sensor network (TEEN) routing protocol into cognitive wireless sensor network. To make routing and spectrum more stable, this paper presents advanced threshold-sensitive energy efficient sensor network (A-TEEN), which is the optimization of TEEN. A-TEEN optimized the cluster head election method compared with TEEN. Simulation result shows that compared with low-energy adaptive clustering hierarchy, TEEN increases the energy efficiency and extends life cycle of cognitive wireless sensor network. A-TEEN improves the energy efficiency and lifetime further operating in the same settings compared with the regular TEEN.
\end{abstract}

Keywords: Cognitive wireless sensor network, TEEN routing protocol, Cluster head election, Energy efficiency

\section{Introduction}

In recent years, the utilization of licensed spectrum is very low resulting in a serious waste of spectrum resources [1]. The proposed of cognitive wireless sensor network (CWSN) effectively address the problem of spectrum scarcity [2]. CWSN combines the characteristics of sensor network and cognitive technology. Cognitive users access the vacant frequencies opportunistically to improve the spectrum utilization. In CWSN, the selection of routing and spectrum are considered to be the most important research hotspots [3].

There are two routing metrics proposed to adjust to CWSN in [4]. The main purpose of this paper is to maximize data rates and minimize delay for a set of user communication sessions. A distributed and efficient cluster-based spectrum and interference aware routing protocol is proposed in [5], the proposed algorithm can well fit into the mobile $\mathrm{CR}$ ad hoc network and improve the network performance. Cognitive low-energy adaptive clustering hierarchy $(\mathrm{CogLEACH})$ was introduced in [6], which is a spectrum-aware extension of the LEACH routing protocol. $\mathrm{CogLEACH}$ is a spectrum-aware and energy efficient clustering protocol for CWSN. The clustering routing protocol LEACH is introduced to CWSN

\footnotetext{
* Correspondence: wangshubin@imu.edu.cn

${ }^{1}$ College of Electronic Information Engineering, Inner Mongolia University,

Hohhot, China

Full list of author information is available at the end of the article
}

in [7], and adapting the cognitive dynamic spectrum environment.

Low-energy adaptive clustering hierarchy (LEACH) has been introduced into CWSN, however, without taking into account the energy efficiency. One of the drawbacks of CWSN is that node energy is limited and cannot be added. It is necessary to use an effective routing protocol to improve energy efficiency and extend the survival time of CWSN. Reducing energy consumption in the process of data transmission is very important in CWSN.

Studies have shown that the design of routing protocols in the CWSN introduces clustering mechanism which can improve network performance. LEACH is a typical cluster routing protocol and is introduced to CWSN. So this article made comparison of LEACH protocol with TEEN protocol, and TEEN protocol with advanced thresholdsensitive energy efficient sensor network (A-TEEN) protocol.

Threshold-sensitive energy efficient sensor network (TEEN) routing protocol is the improvement of LEACH, which is added the hard threshold (HT) and soft threshold (ST) to control the number of data transmission. Introduce TEEN into CWSN, compared with LEACH, can save the energy consumption of nodes and extend the life cycle of network. This paper proposes that use TEEN routing protocol to set up the CWSN. Using the cross-layer design method of network layer and MAC layer, establish the authorized user activity model in 
MAC layer, so that the routing at network layer and the spectrum allocation at MAC layer can cooperate with each other. Join the spectrum detection module to cognitive nodes and add the available channel detection process to the beginning of each round in TEEN algorithm to adapt to the dynamic frequency environment. Simulation results show that, in the same network environment and parameter settings, TEEN reduces the energy consumption of nodes and improves the lifetime of network compared to $\mathrm{LEACH}$.

Based on the limitation of the random cluster head election mechanism of TEEN, this paper introduces A-TEEN, which is an extension of TEEN. A-TEEN uses the number of vacant channels as a weight in the probability of each node to become the cluster head. A-TEEN ensures that the cluster head can communicate with more nodes, reduces the waiting time for node data transmission, and makes routing path become more stable and reliable. Simulation results show that A-TEEN further increases the energy efficiency, improves the network life cycle, and enhances the stability of routing and spectrum compared to TEEN.

\section{Result}

This paper introduces TEEN routing protocol into cognitive wireless sensor network. To make routing and spectrum more stable, this paper presents A-TEEN, which is the optimization of TEEN.

\subsection{CWSN based on TEEN routing protocol}

\subsubsection{Result}

In this part, TEEN routing protocol is introduced into cognitive wireless sensor network. After modeling and simulation in OPNET, we can see that TEEN routing protocol reduced the energy consumption of single node compared with LEACH. The life circle of CWSN under TEEN is longer than that under LEACH. We can know that compared with LEACH, TEEN routing protocol reduced the node energy consumption and delayed the time of node death. From the comparison between the TEEN and LEACH in CWSN, we can come to a conclusion that introducing TEEN routing protocol into CWSN, compared with $\mathrm{LEACH}$, reduces the number of death node and extends the life cycle of network.

\subsection{The optimization of TEEN routing protocol in CWSN}

To make routing and spectrum more stable, this paper presents A-TEEN, which is the optimization of TEEN. A-TEEN optimizes the cluster head $(\mathrm{CH})$ election method of the TEEN and makes routing link more stable and reliable. Compared with TEEN, A-TEEN improves the energy efficiency and life cycle of the network further.

\section{Method}

\subsection{Application of TEEN routing protocol in CWSN}

This paper introduces TEEN routing protocol to CWSN through joining the process of idle channel detection in each round. Due to the limited HT and ST, TEEN reduces unnecessary data transmission a number of times. In order to adapt to spectrum variability of CWSN, this paper joins the process of available channel detection at the beginning of each round.

\subsection{The optimization of TEEN routing protocol in CWSN}

To make routing and spectrum more stable, this paper presents A-TEEN, which is the optimization of TEEN. A-TEEN optimized the cluster head election method compared with TEEN.

A-TEEN uses the number of vacant channels as a weight in probability of each node to become a cluster head. The node which senses more idle channels has bigger opportunity to become $\mathrm{CH}$. The $\mathrm{CH}$ which senses more available channel can establish communication routes with more cluster members. Cluster members can transmit data to their $\mathrm{CH}$ in time to reduce the unnecessary waiting time.

\section{TEEN routing protocol}

TEEN is a reactive clustering routing protocol which is improved by LEACH. The cluster head $(\mathrm{CH})$ of each cluster collects data from its cluster members. $\mathrm{CHs}$ fuse and process data and send data to the BS or higher level $\mathrm{CH}$. All of the nodes only need to transmit data to their $\mathrm{CH}$ and only the $\mathrm{CHs}$ need to aggregate data which is the advantage of the clustering routing protocols. It is energy-saving. All nodes take turns becoming the $\mathrm{CH}$ in order to evenly distribute the energy consumption. $\mathrm{CH}$ election uses the random selection mechanism. Once clusters are formed, $\mathrm{CHs}$ allocate a time slot for cluster members in which the cluster members can transmit their data.

Unlike LEACH, in TEEN routing protocol, $\mathrm{CHs}$ broadcast $\mathrm{HT}$ and ST to their members to control the quantity of data transmission. HT is set based on the range of interest value of users; only when current value of sensed attribute is greater than the value of HT will the nodes transmit sensed data to $\mathrm{CH}$ in the current round. Then, sensed attribute is stored in the sensed value (SV) which is an internal variable. Nodes sense attribute continuously; only when the next value differs from SV by an amount equal or greater than the ST will it be transmitted. The ST reduces the frequency of data transmission by abandoning little change of sensed attribute. The value of ST can be changed according to the needs of users. Setting a smaller ST makes the network more accurate, at the cost of increased energy consumption. 
Thus, users must adjust the size of ST to control the trade-off between energy efficiency and accuracy.

\section{CWSN based on TEEN routing protocol}

\subsection{Application of TEEN routing protocol in CWSN}

Due to the dynamic spectrum characteristics of CWSN, TEEN routing protocol in CWSN is different from a traditional TEEN routing protocol. In CWSN, available channels of each cognitive node are not fixed. It must ensure that two nodes have at least one common idle channel available to communicate. On the basis of statistical correct spectrum sensing results, it builds authorized user activity model in the MAC layer, statistics of authorized users' active characteristics, determines the busy probability of channel, and allocates the channel rationally. The cross-layer optimization of the network layer and MAC layer makes routing protocol more adaptive to the spectrum environment. CWSN model based on TEEN routing protocol is shown in Fig. 1. Cluster members (CMs) in CWSN continue to sense the surrounding data. In the case of satisfying the limits of HT and ST and presenting a common channel with $\mathrm{CH}, \mathrm{CM}$ sends data to $\mathrm{CH}$. After simple data processing and integration, $\mathrm{CH}$ nodes send data to next-level $\mathrm{CHs}$ until data reaches the sink node.

In CWSN, the more active the authorized user is, the more unstable the authorized channel becomes. The activity of authorized users is described by the Semi-Markov ON-OFF process shown in Fig. 2.

As is shown in Fig. 2, the probability of frequency band changing from idle status to busy status is indicated by $p_{i}$ and the probability of frequency band changing from busy to idle is indicated by $q_{i}$. The probability of channel $i$ idle is represented by Eq. (1):

$$
P_{f}=\frac{q_{i}}{p_{i}+q_{i}}
$$

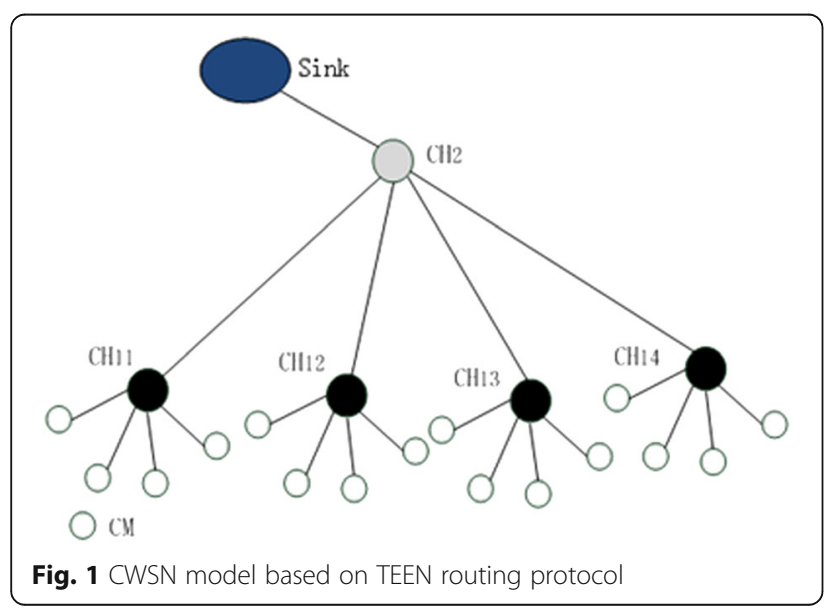

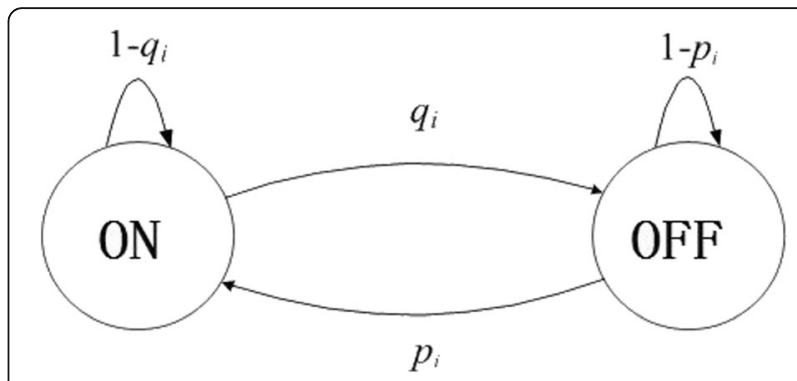

Fig. 2 The semi-Markov ON-OFF model of authorized users

The operation of TEEN consists of many periods. Each period consists of many rounds. The process of $\mathrm{CH}$ election, clustering, and data transmission will be restarted after the end of each round. In order to adapt to spectrum variability of CWSN, this paper joins the process of available channel detection at the beginning of each round. Each node has a set of available channel after the process of available channel detection, such as if node $i$ has the available channel sets $M(i)$, cluster node $j$ has the available channel sets $M(j)$. Once the clusters are formed, $\mathrm{CHs}$ broadcast a time-division multiple access (TDMA) schedule to CMs. TDMA schedule gives the order to $\mathrm{CMs}$ when they can transmit data to $\mathrm{CHs}$ and avoids conflicts between nodes.

In the current round, it is the time shot of node $i$; if node $i$ and cluster head $j$ have a common channel available, node $i$ will send data to cluster head $j$ ordinarily as long as the sensed value meets the requirements of HT and ST. If there are no common channels available between nodes $i$ and $j$, node $i$ in this time slot does not transmit data to $j$ and wait for the next round.

Assuming that CWSN consists of $N$ cognitive nodes, $P$ authorized nodes and the set $M=\{1,2, \ldots, m\}$ of channels. Operation flow chart of TEEN in CWSN contains four stages.

\subsubsection{Stage 1: available channel detection}

At the stage of available channel detection, each node performs the available channel detection process and lists the set of available channel. For example, node $i$ senses the available channel list $M(i)$, which is a subset of $M$.

\subsubsection{Stage 2: cluster head election}

Every node is assigned a random number between 0 and 1 and then computes a threshold formula $T(n)$. If the random number is smaller than $T(n)$, the node decides to become CH. $T(n)$ is computed as Eq. (2):

$$
T(n)= \begin{cases}\frac{P}{1-P^{*}[r \bmod (1 / P)]} ; & ; \in G \\ 0 & ; \text { otherwise }\end{cases}
$$

where $P$ is the percentage of nodes becoming $\mathrm{CHs}$ in each round and $r$ is the current round number. $G$ is the 
set of nodes which have not been elected as $\mathrm{CH}$ in the last $1 / p$ rounds. After the end of each round, the $\mathrm{CH}$ election process will be repeated to ensure every node can be elected as the $\mathrm{CH}$. It ensures the evenly energy consumption of nodes.

\subsubsection{Stage 3: clustering}

After $\mathrm{CH}$ is selected, it broadcasts a message to other nodes to announce itself was elected as $\mathrm{CH}$. The ordinary nodes decide to join the cluster which has the strongest signal. Then it sends a request message to join the $\mathrm{CH}$.

\subsubsection{Stage 4: data transmission}

Nodes sense their environment continuously. $\mathrm{CHs}$ broadcast HT and ST to cluster members. In the data transmission stage of TEEN routing protocol, member nodes transmit data to $\mathrm{CHs}$ under the requirements of HT and ST within their assigned time slot. After a round time, stages $1-4$ is re-initiated.

In summary, in the scenes where spectrum switching frequency is relatively small, TEEN routing algorithm is simple and can meet the spectral fitness. However, when the CWSN spectrum switching is particularly frequent, it makes higher demands on the spectrum fitness of the routing algorithm. This paper presents A-TEEN to improve spectral fitness.

\subsection{The optimization of TEEN routing protocol in CWSN}

Routing protocols in WSN are generally low cost and have low latency as a primary performance indicator. However, on the basis of low cost and low latency, routing protocol in CWSN must take into account the spectral dynamics. So as far as possible to reduce the routing path switching and routing research, maintaining the normal operation of original route will make the route and spectrum more stable.

One of the drawbacks of TEEN routing protocol is $\mathrm{CH}$ random election. The election of $\mathrm{CH}$ is uncontrolled and the randomness is too high. This paper presents the TEEN routing optimization algorithm (advanced threshold-sensitive energy efficient sensor network (A-TEEN) protocol). Measure the noise of electromagnetic environment first, according to the application requirements which preset the range of bandwidth and available channels. A-TEEN uses the number of vacant channels as a weight in probability of each node to become a cluster head. The node which senses more idle channels has bigger opportunity to become $\mathrm{CH}$.

The expected value of $\mathrm{CH}$ number is $k$, in a traditional TEEN protocol; the probability that node $i$ is elected as $\mathrm{CH}$ is given by Eq. (3):

$$
P_{i}(t)=\left\{\begin{array}{c}
\frac{k}{N-k^{*}\left(r \bmod \frac{N}{k}\right)} ; C_{i}(t)=1 \\
0 \quad ; C_{i}(t)=0
\end{array}\right.
$$

In Eq. (3), $k$ is the expected number of $\mathrm{CHs}$ in the network, $N$ is the total number of network nodes, and $r$ is the current round. The probability that node $i$ is elected as $\mathrm{CH}$ is only related to the total number of nodes and the expected number of $\mathrm{CHs}$.

To build a new $P_{i}(t)$, two conditions must be met: (1) Expected $\mathrm{CH}$ number is $k$ and (2) the node which senses more idle channels has bigger opportunity to become $\mathrm{CH}$. Based on the above two requirements, $P_{i}(t)$ is changed to Eq. (4):

$$
P_{i}(t)=\min \left(k \alpha \frac{C_{i}}{m}, 1\right)
$$

where $\alpha$ is a fixed parameter, $m$ represents the total number of channels, and $C_{i}$ represents the number of free channels available to node $i . P_{i}(t)$ is the smallest value between $k \alpha \frac{C_{i}}{m}$ and 1 . If node $i$ senses more idle channel numbers, then $\frac{C_{i}}{m}$ is bigger and the probability that node $i$ is elected as $\mathrm{CH}$ is also bigger.

In order to satisfy the condition (1), it gets Eq. (5):

$$
\begin{aligned}
& k=\sum_{i-1}^{N} P_{i}(t) \\
& k \alpha \frac{C_{1}+C_{2}+C_{3}+\ldots C_{n}}{m}=k \\
& \alpha=\frac{m}{C_{1}+C_{2}+C_{3}+\ldots C_{N}} \\
& P_{i}(t)=\min \left(k \alpha \frac{C_{i}}{\sum_{j=1}^{N} C_{j}}, 1\right)
\end{aligned}
$$

Now, the solution goal is $\sum_{j=1}^{N} C_{j}$.

This paper assumes that the CWSN model is a network model with similar spectrum and space. As shown in Fig. 3, all cognitive nodes are under the coverage of authorized users. Each authorized user has the same occupancy rate for channel, so the free probability of each channel is identical.

$N$ represents the total number of nodes, and the number of free channels that each node can sense satisfies the binomial distribution. It means $\mu=P_{f}^{*} m$. Each node can sense $\mu$ idle channels on average. Then $\sum_{j=1}^{N}$ $C_{j}$ becomes $N \mu$. 


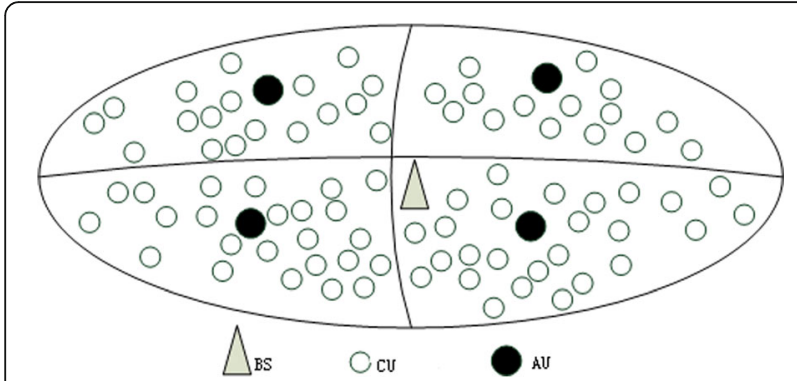

Fig. 3 Space and spectrum similarity CWSN model

$$
P_{i}(t)=\min \left(k \alpha \frac{C_{i}}{N \mu}, 1\right)
$$

A-TEEN algorithm uses Eq. (9) which determines if a node is a cluster head or cluster member in CWSN. The $\mathrm{CH}$ which senses more available channel can establish communication routes with more cluster members. Cluster members can transmit data to their $\mathrm{CH}$ in time to reduce the unnecessary waiting time. A-TEEN algorithm can reduce network energy consumption.

\section{Simulation and analysis}

OPNET is simulation software which is used to model and simulate networks. It uses three layers of modeling mechanism of network, node, and process.

Simulation parameters are as follows: There are 100 cognitive nodes and 10 authorized nodes are randomly deployed in the CWSN. The size of the CWSN is $500 \mathrm{~m} \times 500 \mathrm{~m}$. Five available channels are $<\mathrm{f} 1, \mathrm{f} 2, \mathrm{f} 3$, $\mathrm{f} 4, \mathrm{f} 5>$ respectively, the initial energy of each node equals to $50 \mathrm{~J}$, and idle probability of channel $P_{f}=0.3$. BS is located $(1000 \mathrm{~m}, 1000 \mathrm{~m})$ away from the CWSN.

The network model of CWSN is shown in Fig. 4.

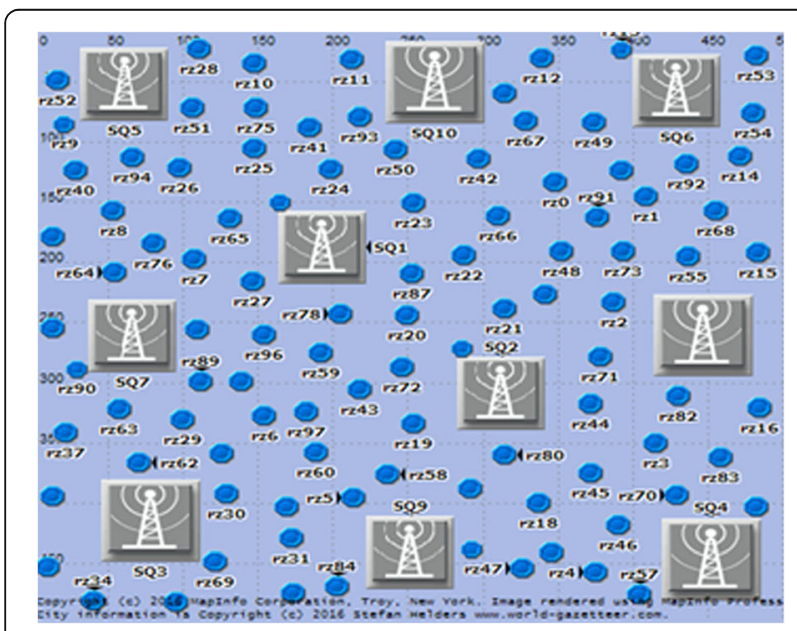

Fig. 4 The network model of the CWSN

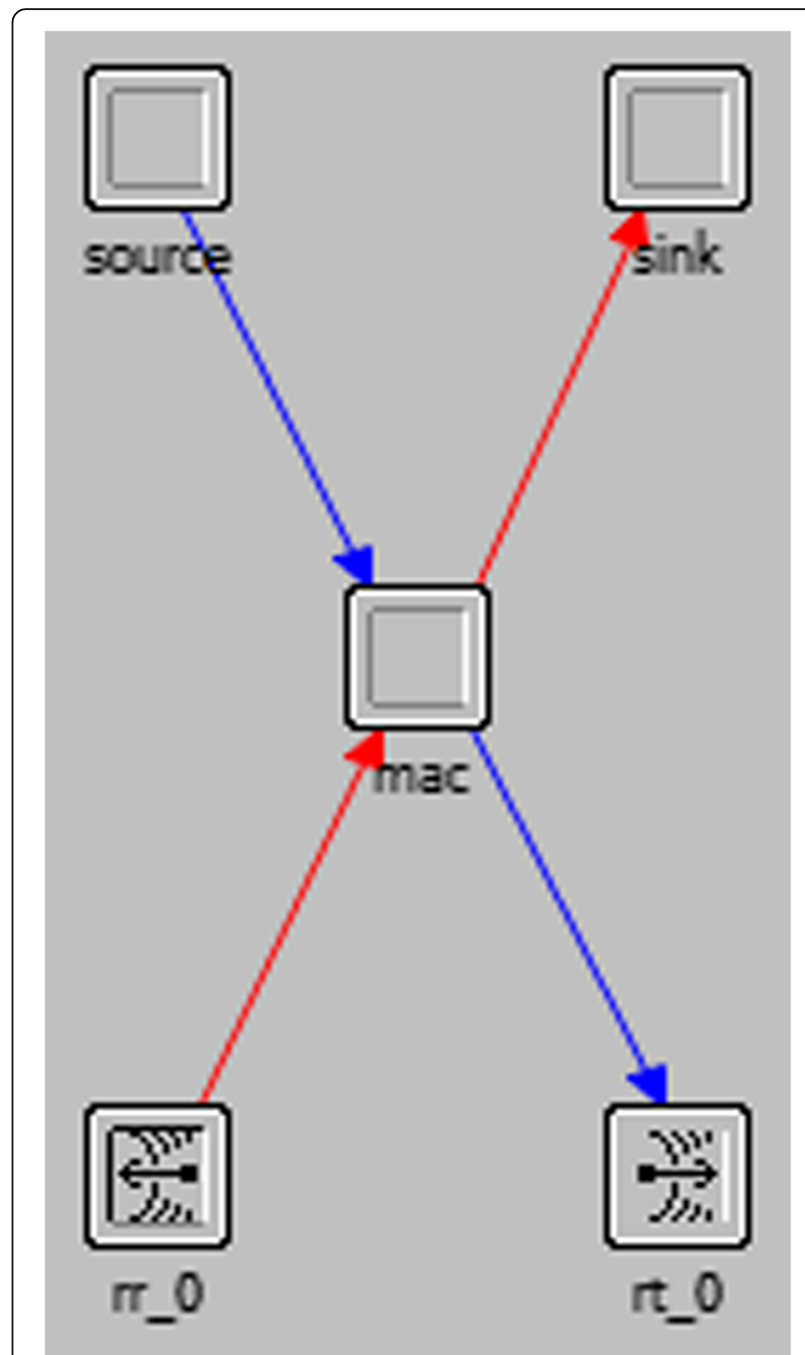

Fig. 5 The node model of authorized nodes

The node model of cognitive nodes and authorized nodes is different. Cognitive nodes need to join the special spectrum monitoring device. Figure 5 shows the node model of authorized nodes. Authorized nodes use OPNET ON-OFF model to achieve its function of packet delivery. In the node model of authorized nodes, you can set the frequency and the use of time. You can also set the ON-OFF model's free and busy state duration. Figure 6 shows the node model of cognitive nodes. Source module generates groups randomly distributed between 0 and 100. The Route module implements the core algorithms of the LEACH, TEEN, and A-TEEN routing protocol. By switching different simulation scenarios, different routing algorithms are simulated and compared.

The process model of TEEN routing protocol in CWSN is shown in Fig. 7. 


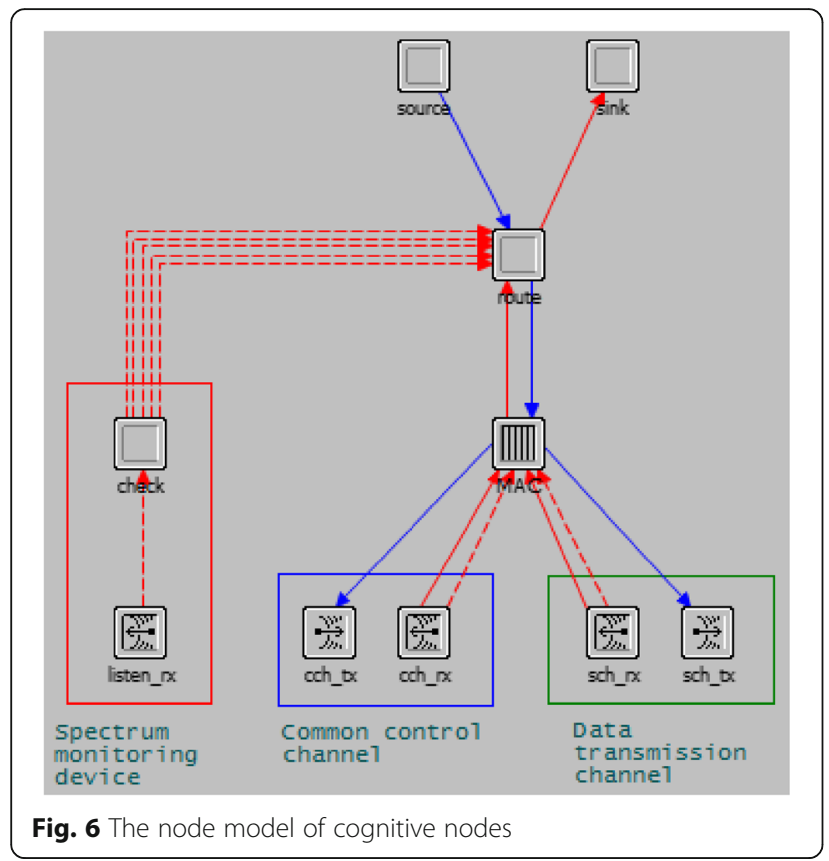

\subsection{Comparison of LEACH and TEEN}

After modeling and simulation in OPNET, choosing one of the cognitive nodes, the energy consumption under LEACH and TEEN routing protocol are shown as Fig. 8. The horizontal axis is the simulation time and the vertical shaft is the node energy $(J)$. The life circle of network comparison between TEEN and LEACH is shown in Fig. 9. The vertical shaft is the number of live nodes.

From the energy consumption simulation diagram of single nodes, TEEN routing protocol reduced the energy

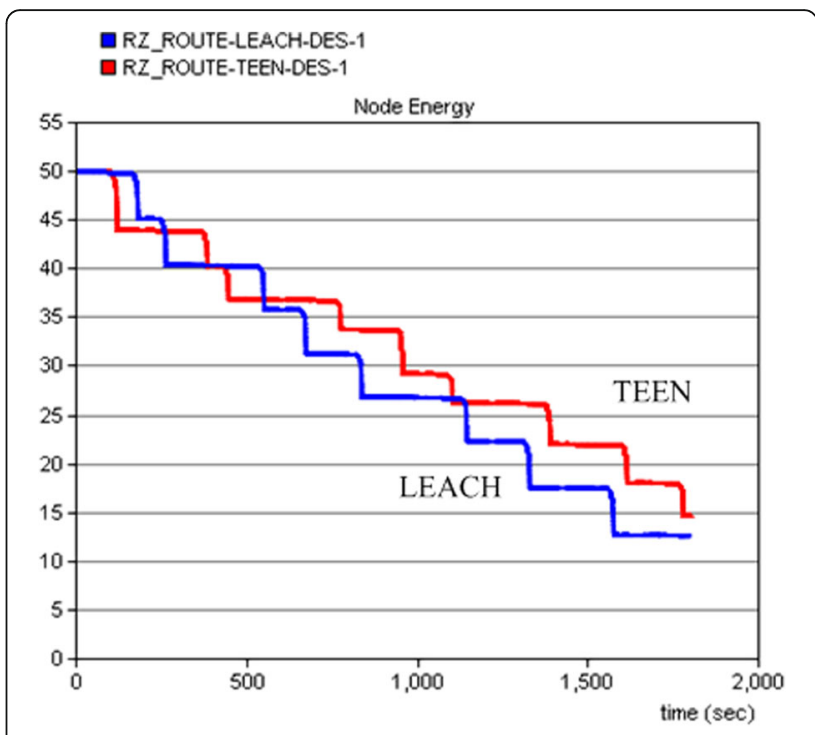

Fig. 8 Energy consumption of single node under TEEN and LEACH

consumption of single nodes compared with LEACH. Figure 9 shows that the life circle of CWSN under TEEN is longer than under LEACH.

Figure 10 shows the number of death node comparison between TEEN and LEACH. The vertical shaft is the number of death nodes. As is shown in Fig. 10, about after $600 \mathrm{~s}$ with LEACH, nodes began to die. However, after about $1000 \mathrm{~s}$ with TEEN, nodes began to die. We can know that compared with LEACH, TEEN routing protocol reduced the node energy consumption and delayed the time of node death. From the comparison

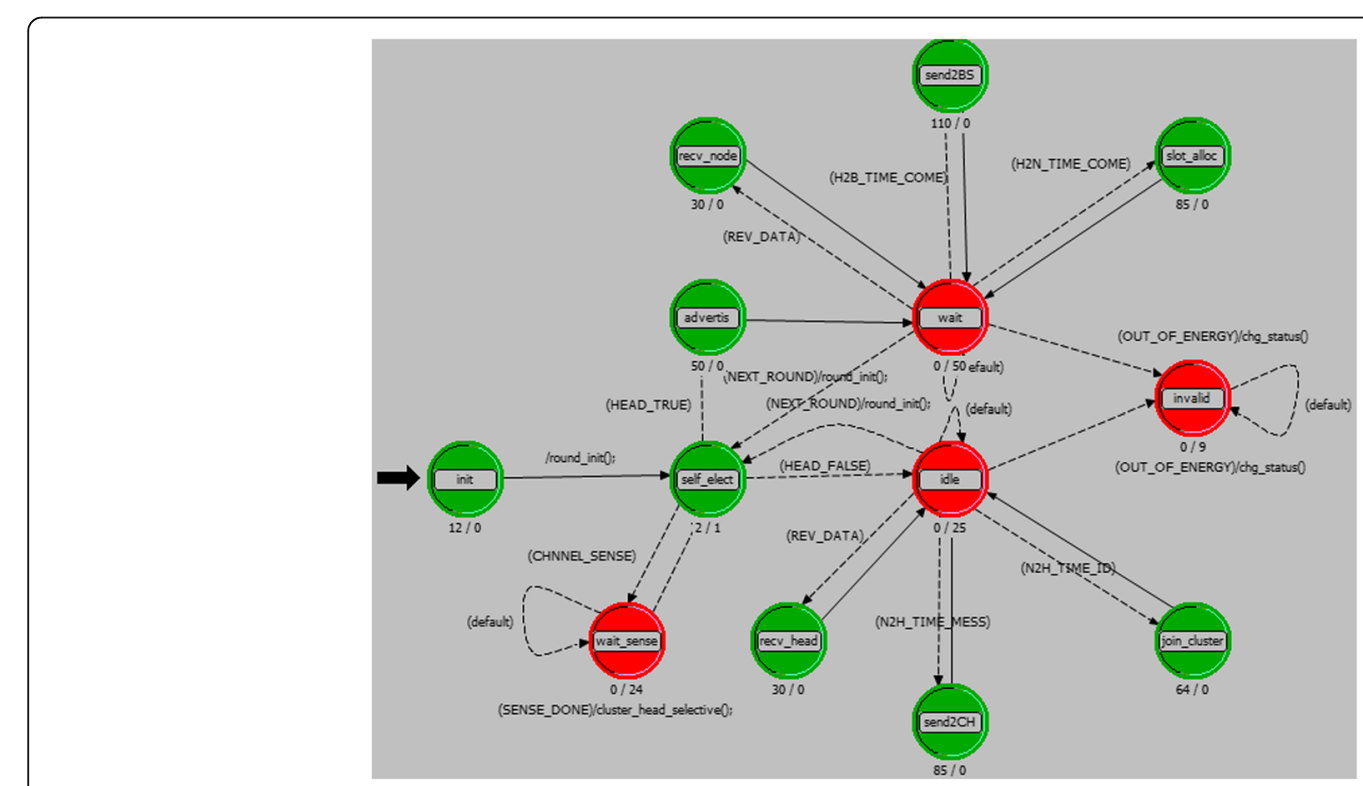

Fig. 7 The process model of TEEN routing protocol in CWSN 


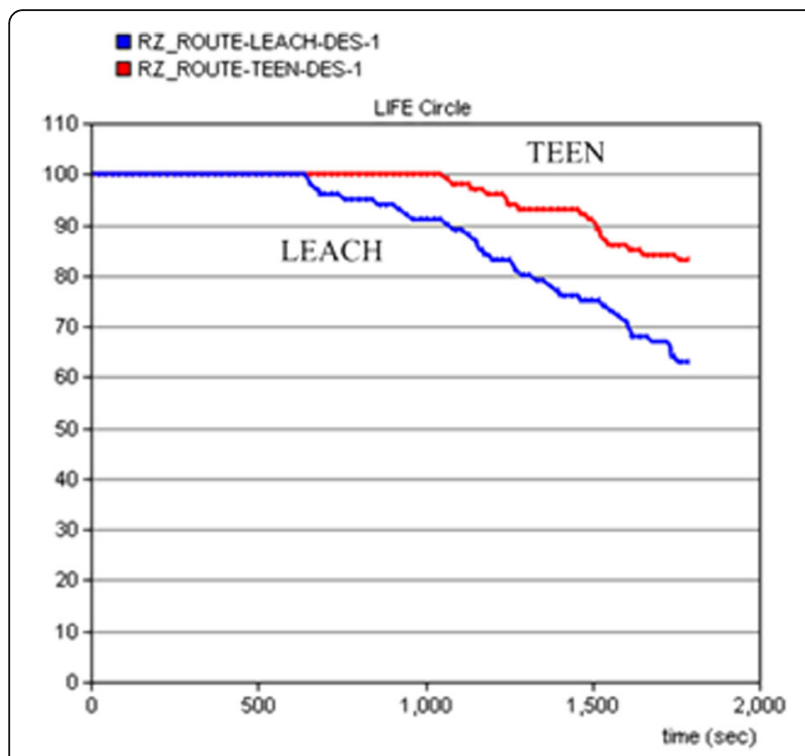

Fig. 9 Life circle of CWSN under LEACH and TEEN

between the TEEN and LEACH in CWSN, we can come to a conclusion that introducing TEEN routing protocol into CWSN, compared with LEACH, reduces the number of node death and extends the life cycle of the network.

Throughput represents the number of data transmission per unit time in the network. Due to the limited HT and ST, TEEN reduces unnecessary data transmission times. Figure 11 is the throughput comparison

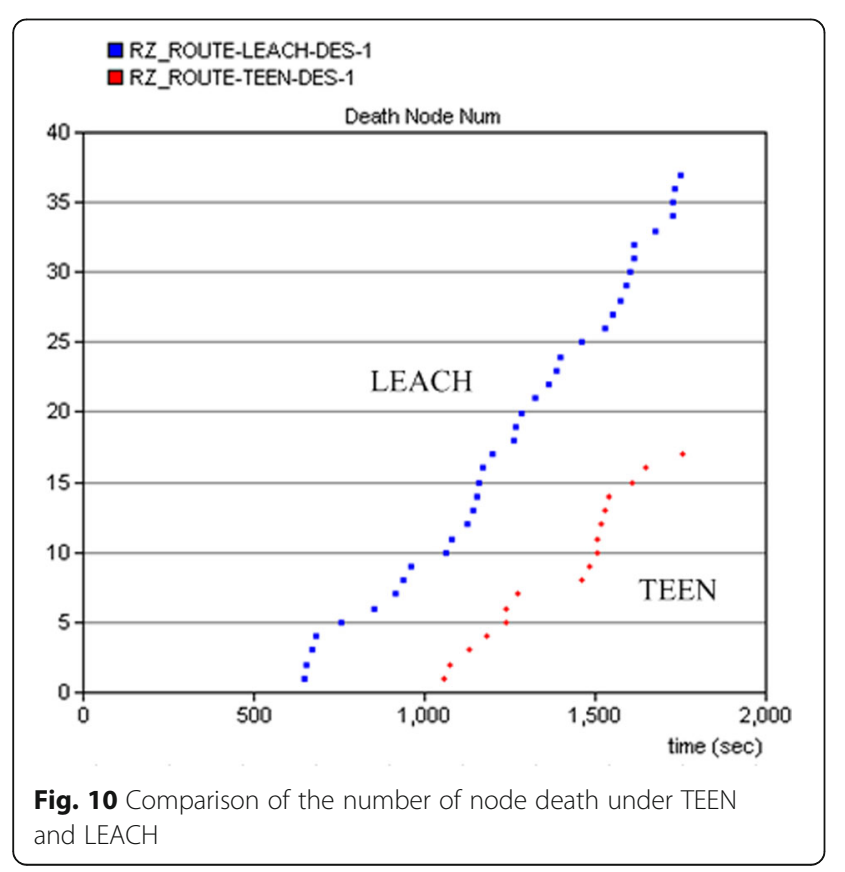

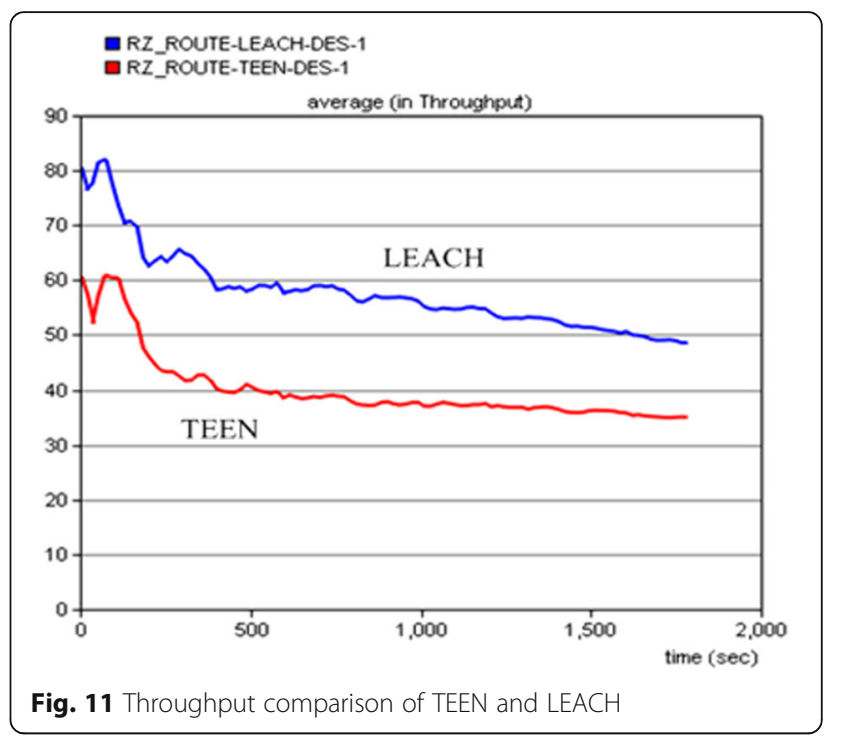

between TEEN and LEACH in CWSN. It shows that throughput of TEEN is lower than that of LEACH.

\subsection{Comparison of TEEN and A-TEEN}

A new A-TEEN scene must be created in route module of node layer to achieve A-TEEN cluster head optimization algorithm. A-TEEN routing algorithm is compared with the TEEN routing algorithm in OPNET. Figure 12 shows the comparison of the available channel numbers of $\mathrm{CH}$ for A-TEEN and TEEN. Figure 13 shows the network lifetime of CWSN under A-TEEN and TEEN. A-TEEN extends the network survival time compared to TEEN.

Figure 14 is the comparison of death node number in CWSN under A-TEEN and TEEN. With the increase of

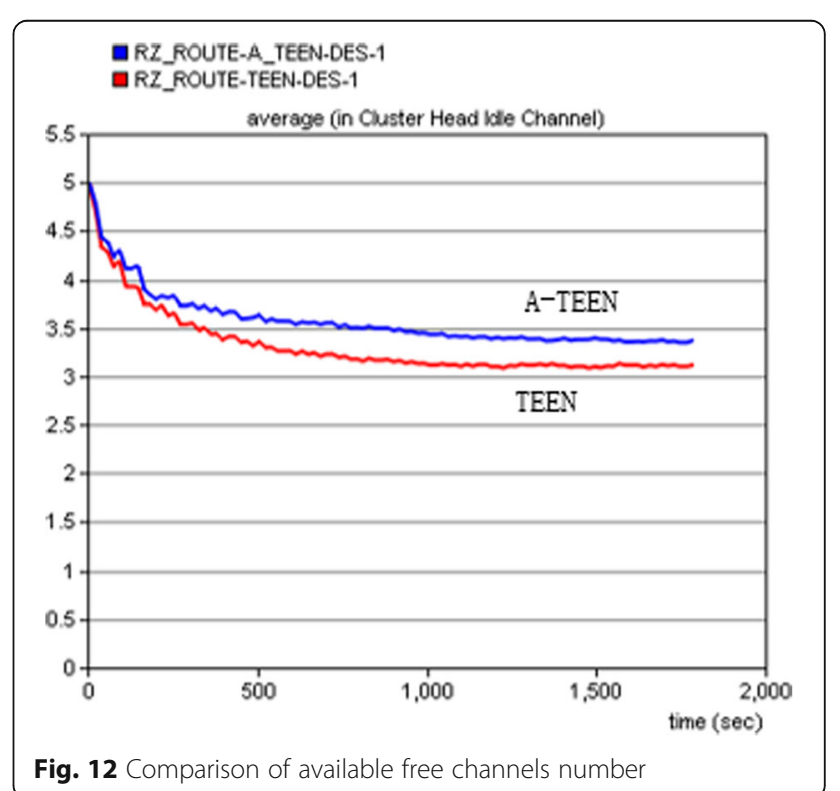




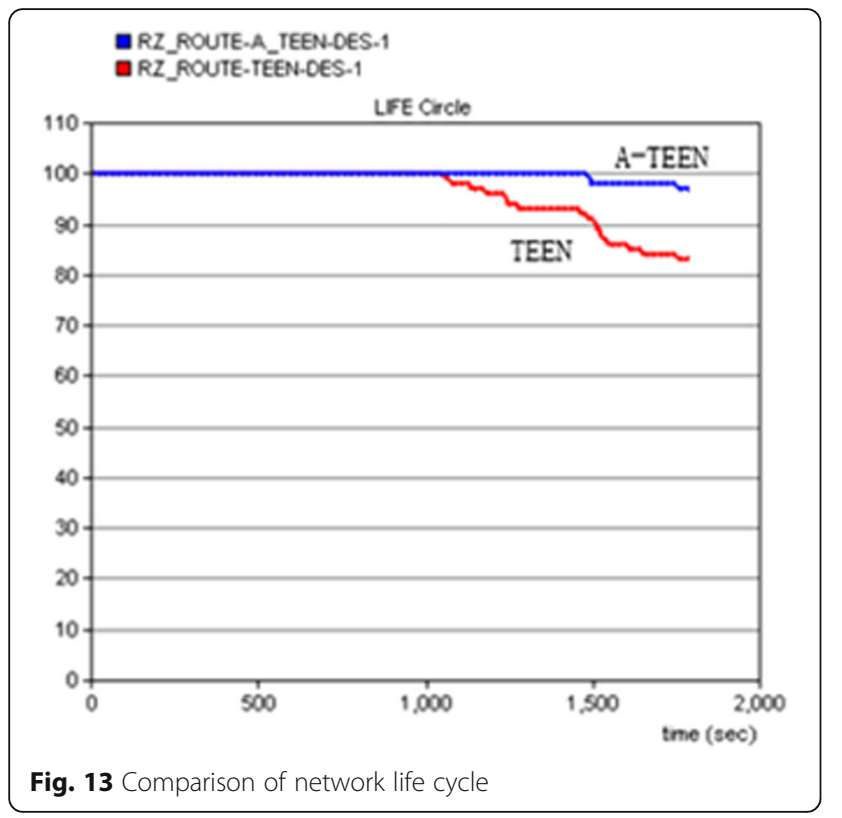

simulation time, death node number under A-TEEN is significantly less than that under TEEN at the same time point. Figure 15 shows the comparison of single node energy consumption in A-TEEN and TEEN. From the figure, we can see that the energy consumption of the A-TEEN routing algorithm is smaller than that of TEEN.

\section{Conclusions}

This paper introduces a TEEN routing protocol to CWSN through joining the process of idle channel detection in each round. Due to the limited HT and ST, TEEN reduces unnecessary data transmission a number

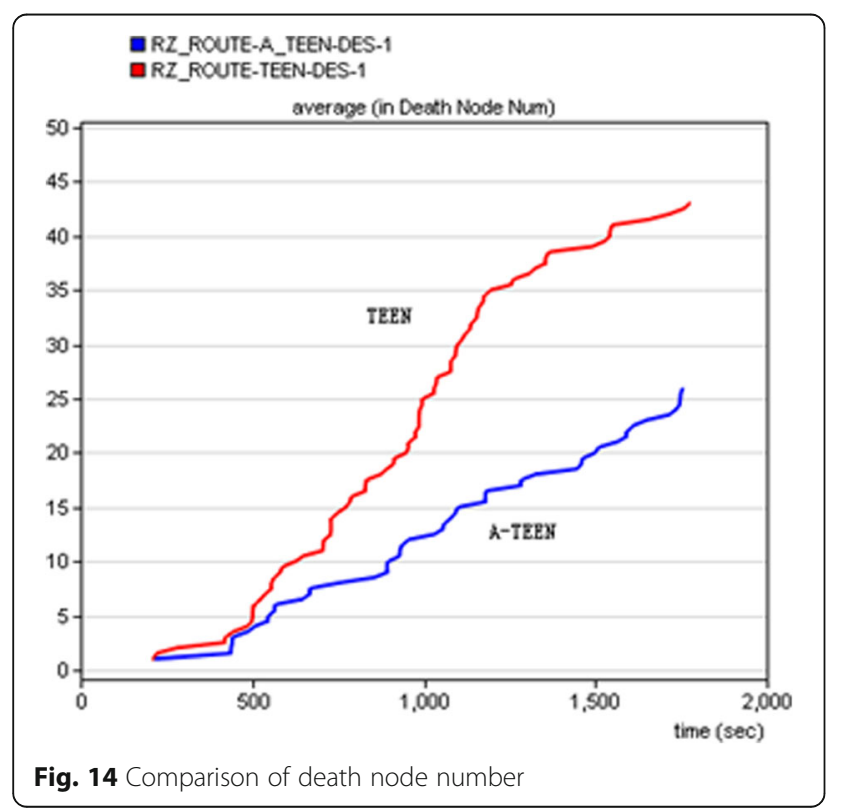

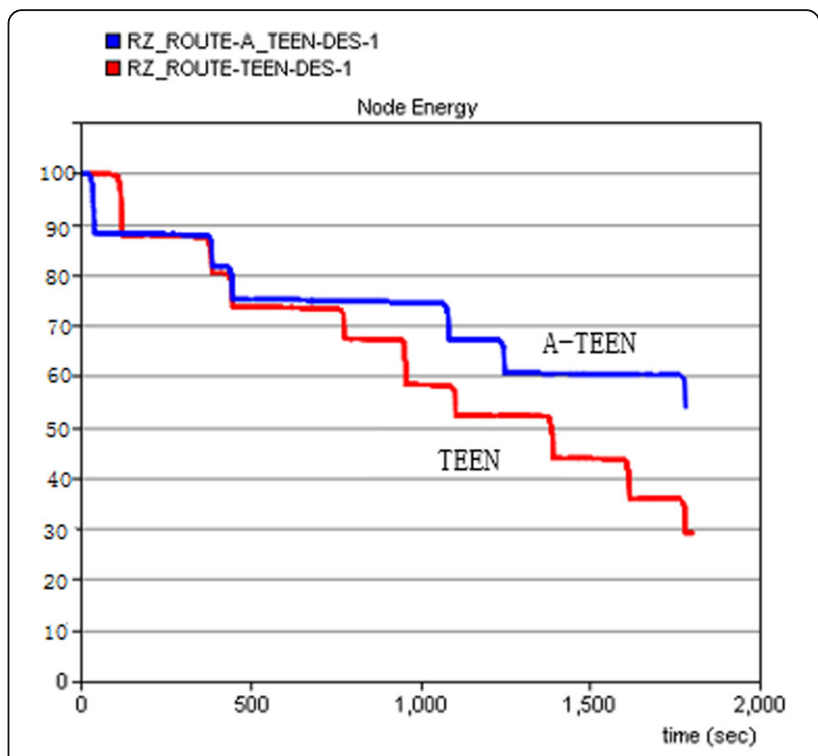

Fig. 15 The energy consumption of a single node

of times. Compared with LEACH, it improved the energy efficiency and delayed the time of node death to extend the network life cycle. Considering the network routing and spectrum stability, this paper presents the optimization algorithm (A-TEEN) of TEEN routing protocol in CWSN. A-TEEN optimizes the $\mathrm{CH}$ election method of the TEEN and makes routing link more stable and reliable. Compared with TEEN, A-TEEN improves the energy efficiency and life cycle of the network further.

\section{Abbreviation}

A-TEEN: Advanced threshold-sensitive energy efficient sensor network; CH: Cluster head; CMs: Cluster members; CWSN: Cognitive wireless sensor network; HT: Hard threshold; LEACH: Low-energy adaptive clustering hierarchy; ST: Soft threshold; SV: Sensed value; TEEN: Threshold-sensitive energy efficient sensor network

\section{Acknowledgements}

Shubin Wang (wangshubin@imu.edu.cn) is the correspondent author, and this work was supported by the National Natural Science Foundation of China $(61761034,61261020)$ and the Natural Science Foundation of Inner Mongolia, China (2016MS0616).

\section{Funding}

This work was supported by the National Natural Science Foundation of China $(61761034,61261020)$ and the Natural Science Foundation of Inner Mongolia, China (2016MS0616).

\section{Availability of data and materials}

All materials and data in this article are available.

\section{Authors' contributions}

The authors propose the introduction of TEEN into the CWSN and the optimization of TEEN routing protocol in CWSN. These two algorithms improved the network performance of the CWSN. All authors read and approved the final manuscript.

Competing interests Not applicable. 


\section{Publisher's Note}

Springer Nature remains neutral with regard to jurisdictional claims in published maps and institutional affiliations.

\section{Author details}

${ }^{1}$ College of Electronic Information Engineering, Inner Mongolia University,

Hohhot, China. ${ }^{2}$ Posts \& Telecom Press, Beijing, China.

Received: 24 October 2017 Accepted: 22 January 2018

Published online: 01 February 2018

\section{References}

1. D Cavalcanti, S Das, J Wang, K Challapali, Cognitive radio based wireless sensor networks. In Computer Communications and Networks, 2008. ICCCN '08. Proceedings of 17th International Conference, 123(6), 1-6 (2008)

2. OB Akan, O Karli, O Ergul, Cognitive wireless sensor networks. IEEE Netw., 216-227 (2009)

3. G Shah, O Akan, Spectrum-aware cluster-based routing for cognitive wireless sensor networks. IEEE International Conference on Communications (ICC), 2885-2889 (2013)

4. A Cagatay Talay, D Turagy Altilar, in International Conference on Ultra Modern Telecommunications \& Workshops. ROPCORN: Routing protocol for cognitive radio ad hoc networks (2009), pp. 1-6

5. AC Talay, DT Altilar, United nodes: Cluster-based routing protocol for mobile cognitive radio networks. IET Commun., 5(15), 2097-2105 (2011)

6. M Eletreby, M Elsayed, M Khairy, CogLEACH: A spectrum aware clustering protocol for cognitive wireless sensor networks. International Conference on Cognitive Radio Oriented Wireless Networks and Communications (CROWNCOM), 179-184 (2014)

7. N Panahi, HO Rohi, A Payandeh, MS Haghighi, Adaptation of LEACH routing protocol to cognitive radio sensor networks. Proc. of the Sixth International Symposium on Telecommunications, 7(1), 541-547 (2012)

\section{Submit your manuscript to a SpringerOpen ${ }^{\circ}$ journal and benefit from:}

- Convenient online submission

- Rigorous peer review

- Open access: articles freely available online

- High visibility within the field

- Retaining the copyright to your article 